ISSN: 2572-7451

\title{
Study Of Anatomical Variation \& Clinical Correlation Of Sacral Hiatus In Dry Human Sacra Of North Indian Population
}

Shivani Chaudhary ${ }^{1 *}$, Anurag Singh ${ }^{2}$

${ }^{1}$ Department of Anatomy, S.G.R.R.I.M \& H.S Dehradun, India.

${ }^{2}$ H.O. D Anatomy S.G.R.R.I.M.\& H.S, Dehradun, India.

\section{Abstract}

\begin{abstract}
Aim: The present study aims at contributing to the existing information related to sacral hiatus which has anatomical variations. Understanding of this variation may improve the reliability of caudal epidural anesthesia and analgesia.

Material \& Methods: The material of the present study consist the 40 dry undamaged human sacra of unknown sex. Which are obtained from the osteology collection held in the Department of Anatomy, Shri Guru Ram Rai Institute of Medical and Health Sciences Dehradun, Uttarakhand, India.

Results: out of 40 undamaged human sacra, in the present study, we observe Inverted ' $\mathrm{V}$ ' shape was most frequent (55\%) followed by inverted ' $U$ ' shape $(35 \%)$. The range of length of sacral hiatus varied between $11-30 \mathrm{~mm}$. The width at base of sacral hiatus varied from 11-15 mm. The depth of sacral hiatus at the level of apex varied between 4-6 mm.

Conclusion: The detailed morphometric study of sacral hiatus is of great relevance, since this route is frequently utilized for caudal epidural anesthesia in perineal surgery and caudal analgesia for a painless delivery.
\end{abstract}

Keywords: Sacrum; Sacral Hiatus; Sacral Canal; Caudal Epidural Anesthesia.

\section{Introduction}

Sacrum is a large flattened triangular bone formed by fusion of five sacral vertebrae. It articulates on either side with the hip bone to form sacroiliac joint. The sacrum presents a base, an apex, pelvic surface, dorsal surface, lateral surface and a sacral canal [1]. The vertebral column is formed from sclerotome of the somites. There are about 44 pairs of somites ( 4 occipital, 8 cervical, 12 thoracic, 5 lumbar ,5 sacral , 8-10 coccygeal somites undergo division into three parts these are (a) dermatome which form part of dermis of the skin (b) myotome which forms skeletal muscle (c) sclerotome - which help to form vertebral column and ribs [2]. Four pairs of pelvic sacral foramina communicate with the sacral canal through inter-vertebral foramina, and transmit ventral rami of upper four sacral spinal nerve. Dorsal surface - the posterosuperior aspect of dorsal surface bears a raised median sacral crest with four spinous tubercles which represent fused sacral spines. Below the fourth (or third) tubercle there is an arched sacral hiatus in the posterior wall of sacral canal. This hiatus is formed by failure of the laminae of the fifth sacral vertebrae to meet in the median plane. Sacral canal - The sacral canal is form by sacral vertebral foramina and is triangular in section. Its upper opening seen on the basal surface, it is directed cranially in the standing position each lateral wall presents four inter-vertebral foramina through which the canal is continuous with the pelvic and dorsal sacral foramina. Its caudal opening is the sacral hiatus.

The canal contains the cauda equina and filum terminale and spinal meninges the lower sacral spinal roots and filum terminale pierce the dura meter and arachnoid mater the filum terminal with its meningeal covering emerges below the sacral hiatus passes downwards across the dorsal surface of the fifth sacral vertebra and sacrococcygeal joint to reach the coccyx. The fifth sacral spinal nerves also emerge through the hiatus medial to the sacral cornua [3-6]. Anesthetic solutions can be injected into the sacral canal through the sacral hiatus. The solutions then act on the spinal roots of the second, third, fourth and fifth sacral and coccygeal segments of the cord as they emerge from the dura mater. The roots of higher spinal segments can also be blocked by this method. The needle must be confined to the lower part of

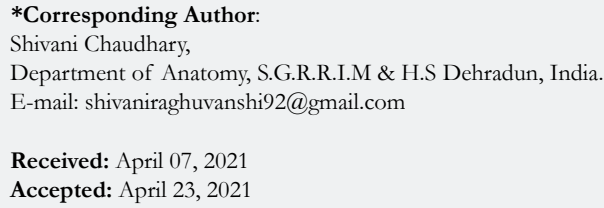

Copyright: Shivani Chaudhary 2021 . This is an open-access article distributed under the terms of the Creative Commons Attribution License, which permits unrestricted use, distribution and reproduction in any medium, provided the original author and source are credited. 
the sacral canal because the meninges extend down as far as the lower border of second sacral vertebra. Caudal anesthesia is used in obstetrics to block pain fibers from the cervix to the uterus and to anesthetize the perineum [7-10].

\section{Material and Methods}

The material of the present study consist the 40 dry undamaged human sacra of unknown sex. Which are obtained from the osteology collection held in the Department of Anatomy, Shri Guru Ram Rai Institute of Medical and Health Sciences Dehradun, Uttarakhand, India. Each sacrum was studied for different features of sacral hiatus by metric \& non-metric method using vernier caliper. The observations noted were analyzed \& compared with previous studies.

\section{Results}

The present study was conducted on 40 dry undamaged human sacra of unknown sex. Variation in the shape of the Sacral Hiatus was grouped under four categories [table.1].

Inverted U [figure.1], Inverted V [figure.2], irregular shape, M shape, $\mathrm{V}$ shape was seen in 22 Sacra (55\%). Both $\mathrm{U}$ and $\mathrm{V}$ shape were considered as normal. Complete Spina bifida seen in only 2 $(1.6 \%)$ [figure.3].

Length of the Sacral Hiatus: The length of the sacral hiatus were $0-11 \mathrm{~mm}$ in 3 sacra $(7.5 \%), 11-20 \mathrm{~mm}$ in 20 sacra (50\%), 20-30 $\mathrm{mm}$ in 10 sacra $(25 \%), 31-40 \mathrm{~mm}$ in 7 sacra $(17.5 \%)$ [Table.2].

Width of the base of Sacral Hiatus: The width of the base of sacrum is $0-5 \mathrm{~mm}$ in 7 sacra $(17.5 \%), 6-10 \mathrm{~mm}$ in 8 sacra $(20 \%)$, $11-15 \mathrm{~mm}$ in $15 \mathrm{sacra}(37.5 \%),>15$ in 10 sacra (25\%) [Table.3].

Depth of the Sacral Canal: The depth of the sacral canal in 4 sacra is $0-3 \mathrm{~mm}(10 \%), 4-6 \mathrm{~mm}$ in 15 sacra $(37.5 \%), 7-9 \mathrm{~mm}$ in 11 sacra $(25 \%),>9$ in 9 sacra $(22.5 \%)$ [Table.4].

They were observed as the following. (Table 1)

Table 1. Shape of Sacral Hiatus.

\begin{tabular}{|c|c|c|c|}
\hline S.No. & $\begin{array}{c}\text { Shape of the } \\
\text { Sacral Hiatus }\end{array}$ & $\begin{array}{c}\text { Number } \\
\text { of Bones }\end{array}$ & $\mathbf{\%}$ \\
\hline 1 & Inverted V & 22 & 55 \\
\hline 2 & Inverted U & 14 & 35 \\
\hline 3 & Irregular & 3 & 7.5 \\
\hline 4 & M-shape & 1 & 2.5 \\
\hline
\end{tabular}

Figure 1. Inverted U Shape.

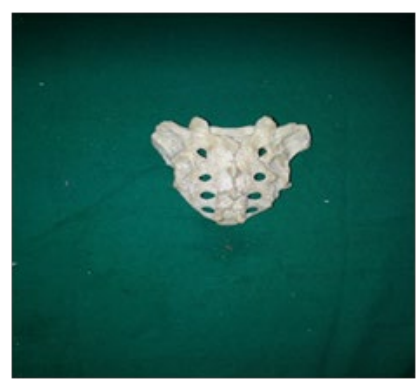

Figure 2. Inverted V Shape.

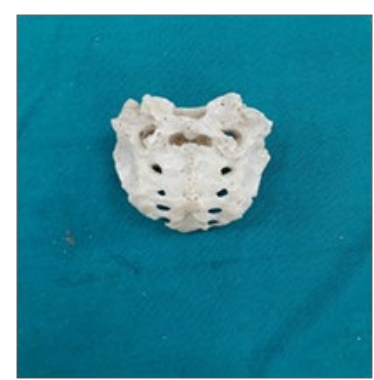

Figure 3. Complete Spina bifid.

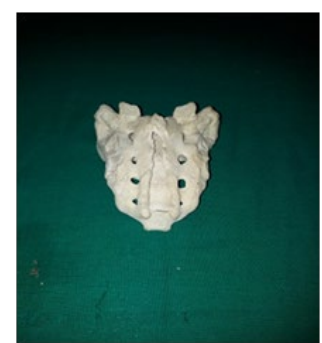


Figure 4. Measurement of Width at Base of Sacral.

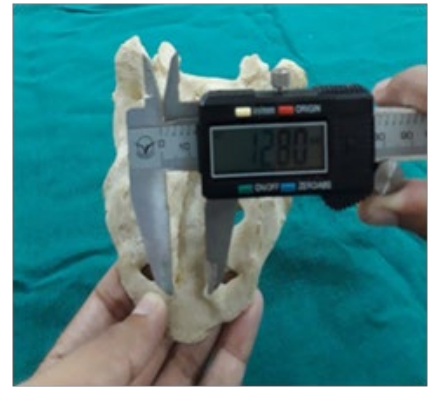

Figure 5. Measurement of Depth of Sacral Hiatus.

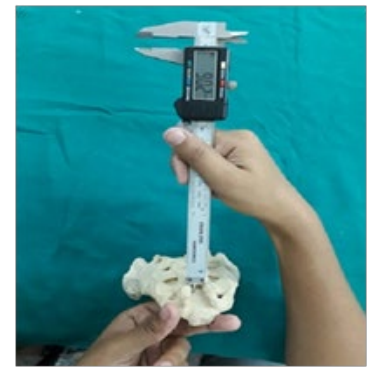

Figure 6. Measurement of Length of sacral Hiatus.

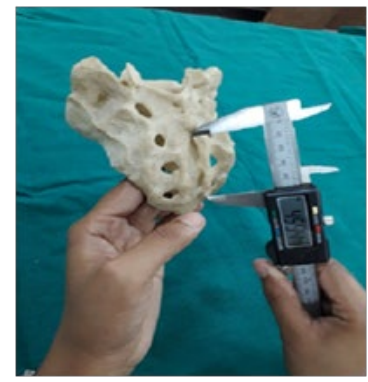

Table 2. Length of Sacral Hiatus from apex to midpoint of base.

\begin{tabular}{|c|c|c|}
\hline Length(mm) & Number & Percentage \\
\hline $0-11$ & 3 & $7.50 \%$ \\
\hline $11-20$ & 20 & $50 \%$ \\
\hline $20-30$ & 10 & $25 \%$ \\
\hline $31-40$ & 7 & $17.50 \%$ \\
\hline
\end{tabular}

Table 3. Width of the sacral hiatus at the base.

\begin{tabular}{|c|c|c|}
\hline Width(mm) & Number & Percentage \\
\hline $0-5$ & 7 & $17.50 \%$ \\
\hline $6-10$ & 8 & $20 \%$ \\
\hline $11-15$ & 15 & $37.50 \%$ \\
\hline $15-20$ & 10 & $25 \%$ \\
\hline
\end{tabular}

Table 4. Depth of sacral canal at the apex of sacral hiatus.

\begin{tabular}{|c|c|c|}
\hline Depth(mm) & Number & Percentage \\
\hline $0-3$ & 4 & $10 \%$ \\
\hline $4-6$ & 15 & $37.50 \%$ \\
\hline $7-9$ & 11 & $25 \%$ \\
\hline$>9$ & 9 & $22.50 \%$ \\
\hline
\end{tabular}




\section{Discussion}

The detailed morphometric study of sacral hiatus is of great relevance, since this route is frequently utilized for caudal epidural anesthesia in perineal surgery and caudal analgesia for a painless delivery. Caudal analgesia is used during surgical procedures in urology, proctology, aneral surgery, obstetrics and gynecology and orthopedics. It is also used for three dimensional colour visualization of lumbosacral epidural space. In orthopaedic practice for diagnosis and treatment. According to Malarvani T et al, (2015) the shapes of sacral hiatus were variable; the most common shape observed was Inverted-U in $35 \%$ of sacra and Inverted- $V$ in $32 \%$ of sacra and Nagar SK [10]. Following studies by Seema [11] Sinha [12] Nadeem [13] Ukoha [14], Akhtar [15] observed that inverted ' $U$ ' shape is the most frequent shape of sacral hiatus followed by inverted ' $\mathrm{V}$ ' shape as observed in the current study. Whereas, Kumar [16] and Nasr [17] observed that inverted ' $V$ ' shape is more common than inverted ' $U$ ' shape.

\section{Length of Sacral Hiatus}

Kumar et al $[18,19]$ observed mean length of hiatus as $20 \mathrm{~mm}$ in males and $18.9 \% \mathrm{~mm}$ in females. In the present study, the length of the sacral hiatus in about $75 \%$ of sacra was $11-30 \mathrm{~mm}$.

\section{Width of Sacral Hiatus}

The width at base of sacral hiatus varied from $0.5-20 \mathrm{~mm}[13,14$, 16]. In the present study, $37.5 \%$ cases it was $11-15 \mathrm{~mm}$.

\section{Depth Of The Sacral Canal}

Commonest range for the depth of sacral hiatus at the level of apex was $4-6 \mathrm{~mm}$ in $37.5 \%$ sacra. This measurement is very important in narrowed sacral canal while introducing needle. Nagar $\mathrm{S}$ K, $4.8 \mathrm{~mm}$ range $(2-14 \mathrm{~mm})$ [11] and Sekiguchi et al 6.0mm [20].

\section{Clinical Significance}

Usually, patients with dorsal wall agenesis of the sacrum are linked with such conditions like posterior disk herniation, backache, enuresis, bowel disorders and weakness of lower limbs. Variations in the development of sacral hiatus can decrease the region for attachment of extensor muscles at the dorsal surface of sacrum resulting in painful condition [21]. Anatomical and developmental variations of the sacral canal and sacral hiatus make sacrum more liable to fracture, difficulty while performing internal screw fixation and other clinical complications. Incorrect needle placement during caudal anesthesia has been linked with intraosseous drug toxicity, and aspiration [22, 23].

\section{Conclusion}

Awareness of anatomical variations of the sacral canal and sacral hiatus is quite essential as a landmark for clinicians to facilitate the procedure of caudal epidural anesthesia to improve its success rate.

\section{References}

[1]. Singh V. Textbook of Anatomy Abdomen and Lower Limb. Elsevier Health Sciences; 2014 Mar 6;2:11-23.

[2]. Singh I. Human embryology. JP Medical Ltd; 2015 Sep 30:142-152.

[3]. Gray's. Gray's Anatomy the Anatomical Basis of Clinical Practice:Back. Elsevier; 2016. 710-762.

[4]. Davivongs V. THE PELVIC GIRDLE OF THE AUSTRALIAN ABORIGINE; SEX DIFFERENCES AND SEX DETERMINATION. Am J Phys Anthropol. 1963 Dec;21(4):443-55. Pubmed PMID: 14185525.

[5]. Fawcett E. The Sexing of the Human Sacrum. J Anat. 1938 Jul;72(Pt 4):633. Pubmed PMID: 17104734

[6]. Singh S, Singh SP. Identification of sex from the humerus. Indian J Med Res. 1972 Jul;60(7):1061-6. Pubmed PMID: 4661453.

[7]. Singh S, Raju PB. Identification of sex from the hip bone-demarking points. Journal of Anatomical Society of India. 1977;26(2):111-7.

[8]. Mahato NK. Variable positions of the sacral auricular surface: classification and importance. Neurosurg Focus. 2010 Mar;28(3):E12. Pubmed PMID: 20192657.

[9]. Mishra SR, Singh PJ, Agrawal AK, Gupta RN. Identification of sex of sacrum of Agra region. J Anat Soc India. 2003;52(2):132-6.

[10]. Nagar SK. A study of sacral hiatus in dry human sacra. J anat Soc india. 2004 Dec;53(2):18-21.

[11]. Singh M, Mahajan A. An Anatomical Study of Variations of Sacral Hiatus in Sacra of North Indian Origin and Its Clinical Significance. International Journal of Morphology. 2013 Mar 1;31(1).

[12]. Sinha MB, Rathore M, Sinha HP. A Study of variation of sacral hiatus in dry bone in central Indian region. International J. of Healthcare and Biomedical Research. $2014 \mathrm{Jul} ; 2(4): 46-52$.

[13]. Nadeem G. Importance of knowing the level of sacral hiatus for caudal epidural anesthesia. Int J Morphol. 2014 Jan 16;31(1):9-13.

[14]. Ukoha UU, Okafor JI, Anyabolu AE, Ndukwe GU, Eteudo AN, Okwudiba NJ. Morphometric study of the sacral hiatus in Nigerian dry human sacral bones. International Journal of Medical Research \& Health Sciences. 2014;3(1):115-9.

[15]. Akhtar J, Fatıma N, Ritu KA, Kumar V. A morphometric study of sacral hiatus and its importance in caudal epidural anaesthesia. International Journal of Anatomy. 2016;5(1):6-11.

[16]. Kumar, V., Pandey, S.N., Bajpai, R.N., Jain, P.N. and Longia, G.S. Morphometrical study of sacral hiatus. J. Anat. Soc. India, 1992;41(1): 7 - 13.

[17]. Nasr AY, Ali YH, ElSawy NA. The sacral hiatus: an anatomic study on both cadaveric and dry bones. Trans Clin Bio. 2014 May;2(1).

[18]. Kumar V, Nayak SR, Potu BK, Pulakunta T. Sacral hiatus in relation to low back pain in South Indian population. Bratisl lek listy. 2009 Jan 1;110(7):436-1.

[19]. Parashuram, R. Morphometrical study of sacral hiatus using isolated dry human sacra. Int. J. Res. Med. Sci, 2015;3: 1726-1733.

[20]. Sekiguchi M, Yabuki S, Satoh K, Kikuchi S. An anatomic study of the sacral hiatus: a basis for successful caudal epidural block. Clin J Pain. 2004 JanFeb;20(1):51-4. Pubmed PMID: 14668657.

[21]. Chhabra N. An anatomical study of size and position of sacral hiatus; its importance in caudal epidural block. IJHSR. 2014;4(12):189-96.

[22]. Brailsford JF. Deformities of the lumbosacral region of the spine. British Journal of Surgery. 1929 Apr;16(64):562-627.

[23]. Ogoke BA. Caudal epidural steroid injections. Pain Physician. $2000 \mathrm{Jul}$ 1;3(3):305-12 